\title{
Seasonal variation of the abiotic parameters and the cladoceran assemblage of Lake Vela: comparison with previous studies
}

\author{
S.C. Antunes, N. Abrantes, F. Gonçalves
}

Departamento de Biologia da Universidade de Aveiro, Campus de Santiago, 3810-193 Aveiro, Portugal. E-mail : sara@bio.ua.pt

\begin{abstract}
Lake Vela is a shallow lake facing eutrophication, like many other freshwater reservoirs. A reduction in biodiversity has been observed and cyanobacterial blooms are frequent, occasionally leading to large fish kills. An annual sampling cycle was carried out in the present study, with the aim of understanding the present seasonal variation of Lake Vela's physico-chemistry and cladoceran assemblage. The present results were compared with those obtained in previous studies. Presently, Lake Vela is facing higher nutrient and Chl $a$ levels than in past years. The cladoceran assemblage is now dominated by small-bodied forms, such as Chydoridae and Bosmina longirostris, except in the spring peak of Daphnia longispina. Still, the seasonal pattern of the cladoceran community is more or less coherent with the general model observed in other temperate lakes. The results also suggest that this was a rather unusual year, with a Daphnia summer peak, probably because of a large fish kill that occurred in late spring.
\end{abstract}

Keywords : cladoceran assemblage, nutrients, physical and chemical parameters, seasonal variation, exotic fish, eutrophication, shallow lakes.

\section{Introduction}

Wetlands have been underrated in terms of their ecological and economic importance. Shallow lakes and small marshes, in particular, are still commonly considered as a nuisance. Many have been drained to eradicate malaria and other diseases; others are used as a sink for all sorts of residues of anthropogenic origin. The vast majority of this type of systems is long facing eutrophication, a process that is accelerated by human activities. The loss of submerged vegetation, the occurrence of algal blooms, the increase in turbidity, and a reduction in biodiversity are some of the characteristics associated with eutrophic lakes, which seriously compromise their wildlife and recreational use (Pereira et al. 2002). Nutrient loading also affects the intricate aquatic food web, including phytoplankton, zooplankton and fish. Zooplankton plays a key role in freshwater lentic ecosystems, due to its pivotal position in bottom-up and top-down feedback mechanisms (Christofferson et al. 1993, Beaver \& Havens 1996,
Jeppesen et al. 1999, Scheffer 1999). Ultimately, zooplankton can function as an indicator of ecosystem health (Hanazato 2001, Pereira et al. 2002).

The aim of this work was to study the seasonal variation of the physico-chemistry and cladoceran assemblage of a shallow eutrophic lake, Lake Vela (Portugal). Some gaps of knowledge exist on the dynamics and ecology of this aquatic system, and the present study intended to explore the influence of environmental and other variables on the seasonal succession of the filter-feeding zooplankton of the lake. Additionally, we intended to compare the present study with previous works in order to comprehend the evolution of the lake status.

Lake Vela is the largest lake of a larger system of interconnected reservoirs, near Figueira da Foz, Portugal (Fig. 1), which are important recreational areas, as well as sources of water for drinking and agricultural purposes. This system is comprised in a coastal belt of dunes and pine forest, sustaining considerable popula- 
tions of amphibians, reptiles, birds (including migratory species) and mammals, several of which are endangered or have a precarious status (Pereira 1997). In spite of its ecological importance, no recent studies exist on the aquatic biological communities of Lake Vela. As to what zooplankton is concerned, only two extensive studies are available: those by Vasconcelos (1990) and by Barros (1994). Fernandes (1999) provided a more recent work on macrophytes and phytoplankton. Toxic algal blooms have become increasingly frequent and large fish kills have occurred in recent years in Lake Vela. Additionally, the fish community was radically altered in recent years, due to the introduction of exotic species (mainly pumpkinseed sunfish). In recent sampling programs (unpublished results from our team) it was possible to observe that Daphnia-dominance periods were short and rare, and that small-bodied forms were usually preponderant. Lake Vela is becoming a progressively more impoverished ecosystem and it is necessary to fully understand its present status in order to implement potential restoration measures.

\section{Materials and methods}

\section{Study site}

Lake Vela is a relatively small (maximum floodable area $70 \mathrm{ha}$ ) and shallow (0.9 m average depth; $2.4 \mathrm{~m}$ maximum depth) water body in the centre of Portugal (Figueira da Foz, Fig. 1). It is highly eutrophic, mainly because of regular nutrient inputs from adjacent agricultural fields. The water is permanently turbid throughout the year and algal blooms are frequently observed, including some toxic species, predominantly $\mathrm{Mi}$ crocystis aeruginosa (Vasconcelos et al. 1993, Barros 1994, Fernandes 1999). Besides Cyanophyta, diatoms (especially Cyclotella sp.) generally dominate phytoplankton, but large fluctuations on phytoplanktonic taxa have been observed (Vasconcelos 1990, Barros 1994, Fernandes 1999). Approximately $80-90 \%$ of the flooded lakebed does not contain any vegetation (Fernandes 1999), probably due to the lake's high turbidity. Emergent macrophytes (especially Cladium mariscus and Phragmites australis) are abundant in the shoreline and small beds of water lilies (Nymphaea alba) are also common in some areas of Lake Vela, all year long. Submerged macrophytes (Chara sp.) occur during spring and summertime, but only in restricted areas of the lakebed (Fernandes 1999).

Zooplankton is clearly dominated in numbers by rotifers (especially Keratella sp.), but cladocerans are al-

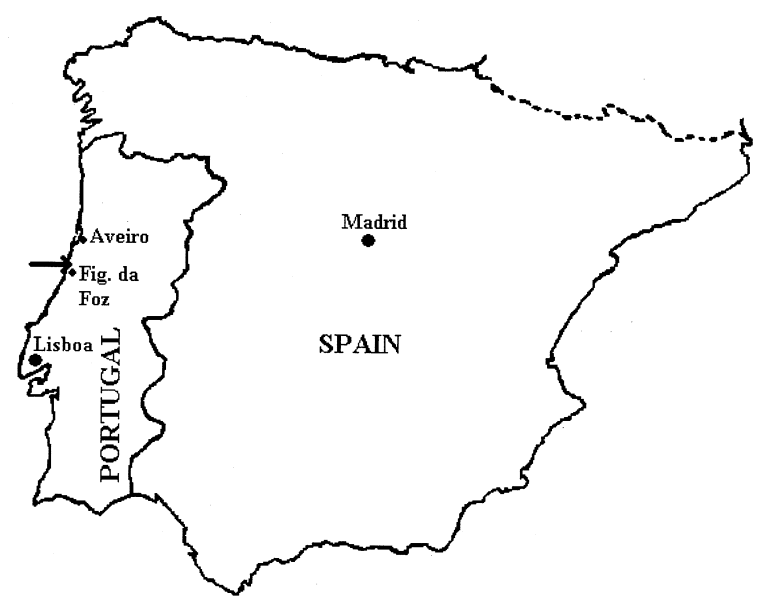

Fig. 1. Location of Lake Vela.

so important in terms of abundance, especially during spring and autumn (Barros 1994). Furthermore, cladocerans represent the largest component of zooplankton in terms of biomass, and are the major filter-feeders, along with copepods. Daphnia longispina, Bosmina longirostris and Ceriodaphnia pulchella are the dominant cladoceran species in Lake Vela (Barros 1994, Pereira 1997). Fish are also very abundant and, at the present, the dominant species are pumpkinseed sunfish (Lepomis gibbosus), mosquitofish (Gambusia holbrooki) and large-mouth bass (Micropterus salmoides), which are all non-native. The fish community has been radically changing, especially since the introduction of sunfish in the late $90 \mathrm{~s}$, which lead to the local extinction of once abundant native species, such as loach (Cobitis maroccana) or eel (Anguilla anguilla) (Pereira 1997).

\section{Sampling procedures}

A sampling site in the central part of Lake Vela was chosen for the study, in a macrophyte-free area (open water). Sampling took place every two weeks over a period of one year (October 2000 - October 2001) and the average depth recorded during this time was $1 \mathrm{~m}$. Fieldwork always started in late morning, so that it would be complete around midday (all measurements and samples were therefore taken at the same approximate hour of the day, for the whole duration of the study). Prior to sampling, pH (WTW 340-A pH meter), dissolved oxygen (WTW OXI 320 oxygen meter), temperature and conductivity (WTW LF 330 conductivity meter) were measured subsuperficially. 
Water samples were collected at the surface with 1.5-L plastic bottles for later quantification of photosynthetic pigments and suspended solids, as well as for chemical analysis (nutrients, alkalinity and hardness). All bottles were immediately placed in the dark, at $4^{\circ} \mathrm{C}$. As soon as possible, samples for chemical determinations were frozen at $-20^{\circ} \mathrm{C}$, until further processing (see below). After collection, a set of water samples was filtered through a Whatman GF/C filter (1.2 $\mu \mathrm{m}$ porosity, $47 \mathrm{~mm}$ diameter) for photosynthetic pigments quantification (in triplicate). Filters were then ground in $90 \%$ acetone and stored in the dark at $4^{\circ} \mathrm{C}$ for $24 \mathrm{~h}$, to complete pigment extraction (Strickland \& Parsons 1972, Lind 1979). After a short centrifugation, the absorbance of the extracts was read at $665 \mathrm{~nm}$ and $750 \mathrm{~nm}$ (in a Spectronic 20 Genesys spectrophotometer), before and after acidification with $\mathrm{HCl}$. Chlorophyll $a(\mathrm{Chl} a)$ and phaeophytin concentrations were calculated according to Lorenzen's (1967) monochromatic equations. Another set of water samples was filtered through pre-weighed GF/C filters, for determination of suspended solids (in triplicate). Suspended solids (volatile and fixed) were calculated after obtaining the dry weights (dried at $60^{\circ} \mathrm{C}$ for $24 \mathrm{~h}$ ) and ash-free dry weights (ignited at $450^{\circ} \mathrm{C}$ for 8 h) of the filtered residues (adapted from Lind 1979, APHA et al. 1989).

Later in the laboratory, samples for chemical determinations were thawed and analyses were performed according to each parameter. Ammonia was determined by the Nessler method, nitrate by cadmium reduction, nitrite by a colorimetric method and soluble reactive phosphorous (SRP) by the ascorbic acid method, following the recommendations and procedures of Strickland and Parsons (1972), Lind (1979) and APHA et al. (1989). Alkalinity and hardness were determined through buret titration methods, according to APHA et al. (1989).

For zooplankton analysis, three replicate samples were collected and concentrated by filtration through a 55- $\mu \mathrm{m}$-mesh screen until significant clogging occurred. For this reason, the volume of water that was filtered varied according to the concentration of plankton in the water column (from 5 to $25 \mathrm{~L}$ of filtered water per replicate sample). Each nylon screen was immediately placed in sucrose-saturated $4 \%$ formalin (Haney \& Hall 1973) for zooplankton preservation. In the laboratory, zooplankton samples were sorted out and cladoceran taxa were identified, using the keys of Scourfield \& Harding (1966) and Amoros (1984a, 1984b), and enumerated.

\section{Statistical analysis}

Average cladoceran abundance and environmental variables values for each date were used to build the data matrices. Prior to analysis, zooplankton abundances were log transformed and environmental variables were standardized. Canonical correspondence analysis or CCA (ter Braak 1986) was used to explore the zooplankton abundance matrix and the physical and chemical data matrix. CCA is an eigenvalue ordination technique developed to analyse relationships between multivariate ecological data matrices (ter Braak 1995, ter Braak \& Verdonschot 1995). As correspondence analysis, CCA allows exploring trends in zooplankton abundance, while, at the same time, enabling the researcher to ascertain relationships between species data and environmental variables. CCA extracts synthetic gradients from the biotic and environmental matrices, which are quantitatively represented by arrows in graphical biplots (ter Braak 1995). The length of the arrow is relative to the importance of the explanatory variable in the ordination, and arrow direction indicates positive or negative correlations (for further explanation, see ter Braak 1995). A Monte Carlo permutation test was used to assess the significance of the relation between zooplankton data and the explanatory variables.

\section{Results}

Photosynthetic pigments were fairly variable during the sampling period (Fig. 2). Chl $a$ was highest in the warmer months (June-September), attaining a peak of $149 \mathrm{mg} / \mathrm{m}^{3}$ in May 16. This peak preceded a large fish kill in Lake Vela, two weeks later (May 29). Suspended solids (Fig. 2) were mainly constituted of organic materials (volatile at $450^{\circ} \mathrm{C}$ ) and presented their lower values during winter and early spring (January-May). The highest values of suspended solids were observed in the summer and early autumn. Water temperature was lower in the winter and higher in the summer (Fig. 2). The maximum attained was $29.4^{\circ} \mathrm{C}$ in July and the lowest temperature was recorded in January $\left(11.5^{\circ} \mathrm{C}\right)$. Oxygen levels (Fig. 2) were constant during the sampling period, with few exceptions; a noticeable case was the complete oxygen depletion $(0 \mathrm{mg} / \mathrm{L})$ recorded in May 29, which corresponded to a large fish kill. Conductivity and $\mathrm{pH}$ values were relatively constant during the sampling period, as observed in Fig. 2.

Fig. 3 shows the variation in the water chemistry during the sampling period. Nutrient concentrations, especially for nitrate $\left(0.30-3.60 \mathrm{mg} / \mathrm{L} \mathrm{N}^{-N^{-}}{ }_{3}^{-}\right)$and orthophosphate $\left(0.00-1.65 \mathrm{mg} / \mathrm{L} \mathrm{PO}_{4}{ }^{3-}\right)$, were relatively 

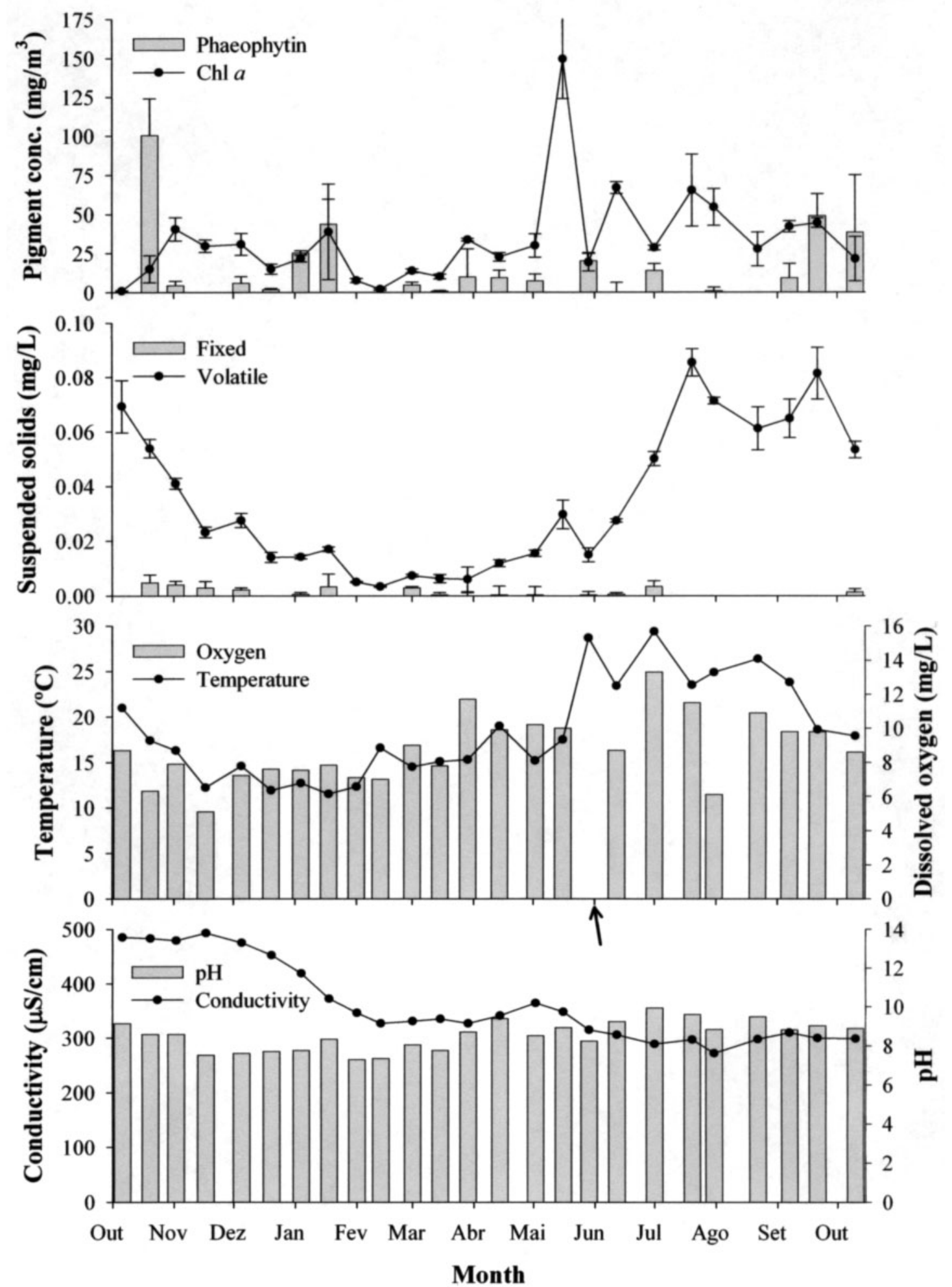

Fig. 2. Variation of photosynthetic pigments (Chl $a$ and phaeophytin), suspended solids (volatile and fixed), and physical and chemical parameters (temperature, dissolved oxygen, conductivity and $\mathrm{pH}$ ) during the studied period. Error bars represent standard deviation. 
high. The highest concentrations of nutrients were observed from December to April, probably deriving from adjacent soil leaching, promoted by rains. Nitrites, nitrates and orthophosphates (SRP) showed a similar pattern, while ammonia had a more discrete peak. Another peak in ammonia was recorded during the fish kill, in late May 29. Alkalinity and hardness were more or less constant during the study period.

Daphnia longispina was not detected from Lake Vela from October to December, but became the most abundant cladoceran during early spring (February-
April) (Fig. 4). It then peaked during the summer, reaching its highest density in August and September (318 ind./L). Ceriodaphnia pulchella was also absent from October to December and its densities were very low all year long (Fig. 4), attaining its highest densities from February to June. A peak (28 ind./L) was observed in May, corresponding to $\mathrm{Chl} a$ highest value (Fig. 2). Bosmina longirostris and Chydoridae were, by far, the most abundant cladocerans in Lake Vela (Fig. 4). During the period where Daphnia and Ceriodaphnia were absent, $B$. longirostris and Chydoridae attained very high densities (approx. 1000-1500 ind./L). Du-
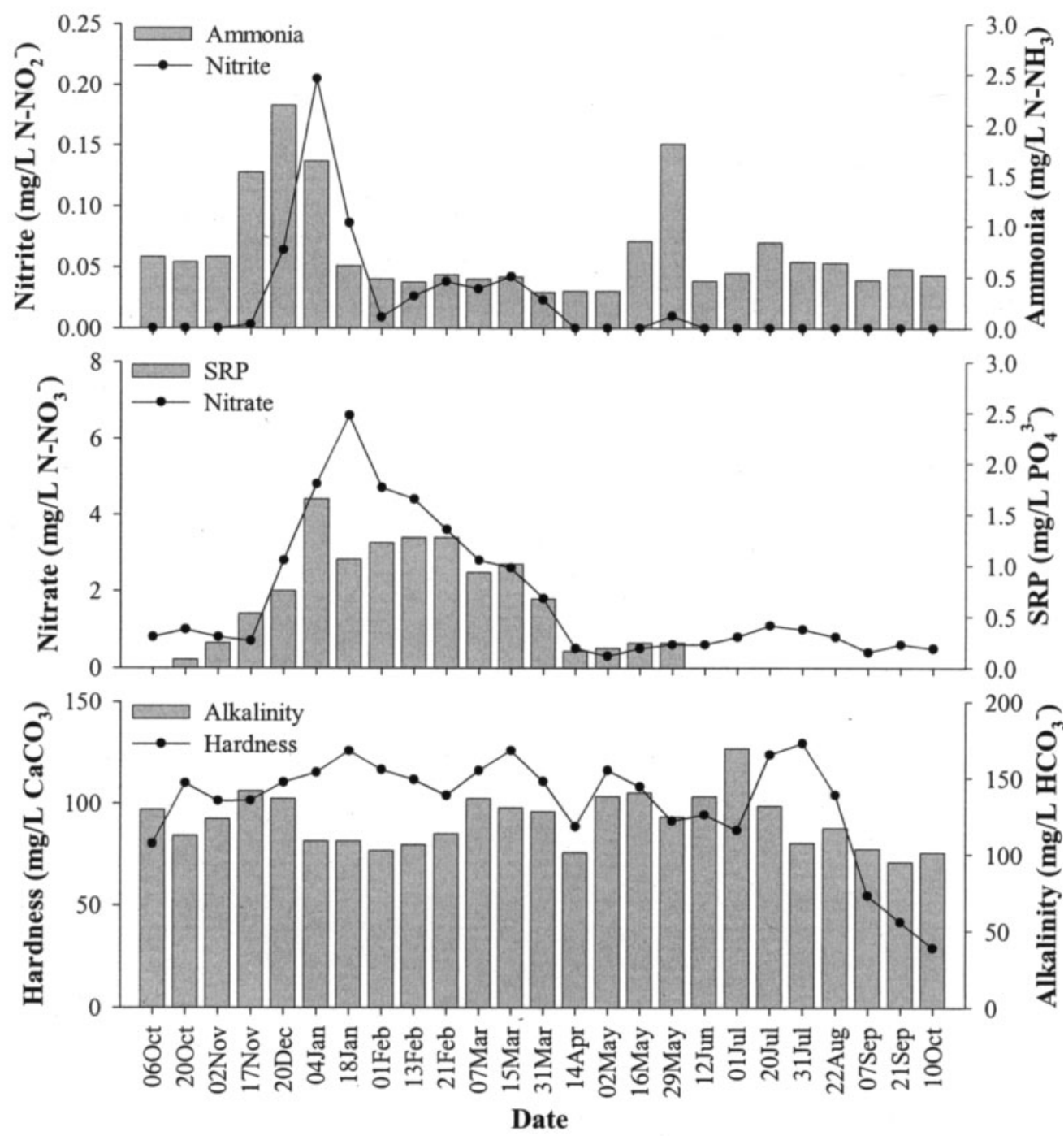

Fig. 3. Variation of nutrients (nitrite, ammonia, nitrate and soluble reactive phosphorous - SRP), hardness and alkalinity during the studied period. 

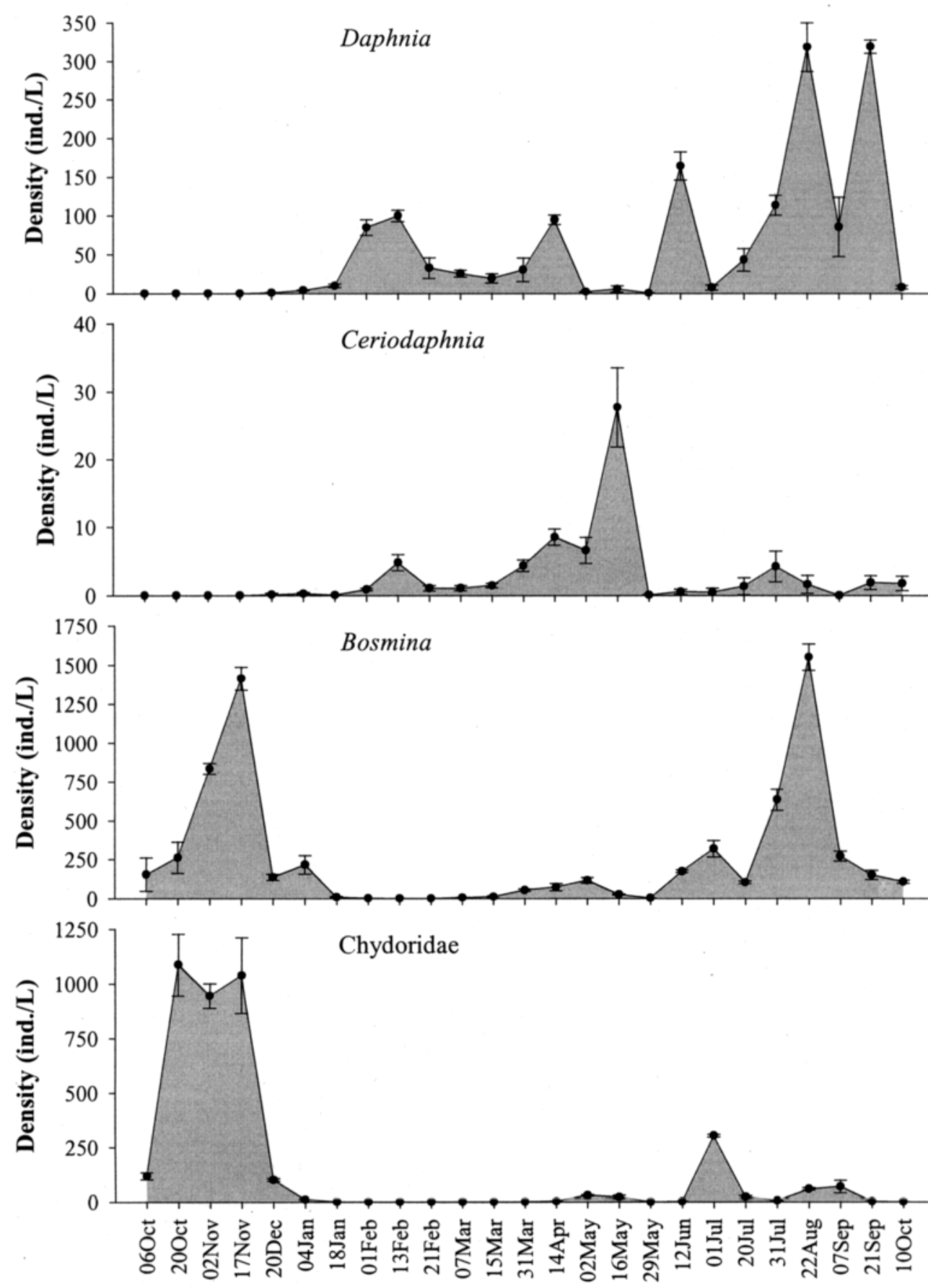

Date

Fig. 4. Variation of main cladoceran taxa densities during the studied period. Error bars represent standard deviation. 
ring spring, in the Daphnia-dominated period, these small taxa presented low densities, especially Chydoridae. Bosmina longirostris became again the most abundant cladoceran in the summer, reaching its maximum density in August (1551 ind./L). Chydoridae also attained high densities in the summer, although not as pronounced as B. longirostris. Still, this summer peak was far beyond the highest densities observed for Chydoridae, which were observed in October/November (1000 ind./L, in average). Practically no cladocerans were found when the large oxygen depletion and fish kill occurred (May 29), including $C$. pulchella $(0.2$ ind./L), which had had a sudden burst two weeks before (May 16).

Ordination resulting from CCA produced the species-date biplot presented in Fig. 5A. First of all, ordination showed an association between $B$. longirostris and Chydoridae. Both $C$. pulchella and D. longispina are somewhat further apart. Sampling dates closer to Bosmina and Chydoridae mainly correspond to winter months, where these two small-sized taxa dominated the cladoceran assemblage. The majority of the remaining sampling dates are associated with either Daphnia or Ceriodaphnia. The latter taxon was absent or in very low densities in most part of the year: its abundance peaks, although not very extensive, greatly influenced the ordination of some sampling dates. The most obvious example is May 16, which corresponds to the maximum Ceriodaphnia densities observed during the study period. This point also corresponds to the maximum Chl $a$ values observed and it preceded a major fish kill (May 29).

The 14 environmental variables considered in the CCA explained $34 \%$ of the total variation of the cladoceran assemblage. The first two axes of the speciesenvironmental variables biplot (Fig. 5B) alone accoun-

Table 1. Summary of CCA between cladoceran abundance and environmental variables for the studied period in Lake Vela. The statistics are only presented for the first two axes.

\begin{tabular}{lcc}
\hline & Axis 1 & Axis 2 \\
\hline Eigenvalues & 0.279 & 0.042 \\
Species-variable correlations & 0.983 & 0.844 \\
Cumulative percentage variance & 74.0 & 85.3 \\
$\quad$ of species data & 82.2 & 94.8 \\
$\quad$ of species-variable relation & 0.377 \\
Sum of all unconstrained eigenvalues & 0.340 \\
Sum of all canonical eigenvalues & \multicolumn{2}{c}{$32 \%$} \\
Variance explained & \multicolumn{2}{c}{0} \\
\hline
\end{tabular}

ted for $32 \%$ of the total variability (Table 1 ). Although the species-variable correlations were high, the eigenvalues for the first two axes were relatively low. Still, a Monte-Carlo simulation showed statistical significance $(P \leq 0.005)$ in the relation between cladoceran abundance and the abiotic factors. Clear trends are difficult to extract, mainly because of the proximity of the species scores (Fig. 5B). However, Chl $a$ and oxygen appear to be influent variables, which is probably related to the Chl $a$ peak (May 16) and subsequent oxygen depletion on the occasion of the fish kill of May 29.

\section{Discussion}

Lake Vela is a eutrophic shallow lake with high $\mathrm{P}$ and $\mathrm{N}$ levels and its zooplanktonic community has low diversity and it is normally very abundant (Pereira 1997). Cyanobacteria blooms are frequent, especially Microcystis (Vasconcelos 1990, 1993), and fish kills have occurred in the last years. Submerged macrophytes are usually scarce, planktivorous fish now dominate, and chlorophyll $a$ is higher during the summer months. This description is in agreement with the findings of Jeppesen et al. (1999) on eutrophic turbid lakes. Lake Vela is clearly a turbid lake, threatened by eutrophication and is also facing the proliferation of exotic fish species. Previous studies on Lake Vela have shown a cladoceran assemblage highly abundant in the period between July and November. Barros (1994) showed a Daphnia-dominated community in the spring period and a Ceriodaphnia-dominated period in the summer. Chydoridae and Bosmina were present all year long at low densities, but the latter taxon was highly abundant in the beginning of the summer and early autumn. Vasconcelos (1990) only studied the zooplankton community during the summer, but his results were in agreement with those of Barros (1994). In summary, D. longispina and B. longirostris were the dominant species in the beginning of the summer, but they were quickly replaced by $C$. pulchella during the rest of the summer.

These past studies have been discontinuous and, since then, the fish community has changed due to the proliferation of exotic species. Discrepancies arise when one compares the present study with these former works. Nutrients had a similar pattern to what was observed in previous studies; however, higher nutrient concentrations (mainly nitrates and phosphates) were recorded in the present study. Average Chl $a$ concentrations were also much higher in this study than in the one by Barros (1994). It is possible, therefore, that Lake Vela is now more eutrophic than 10 years ago. Gon- 

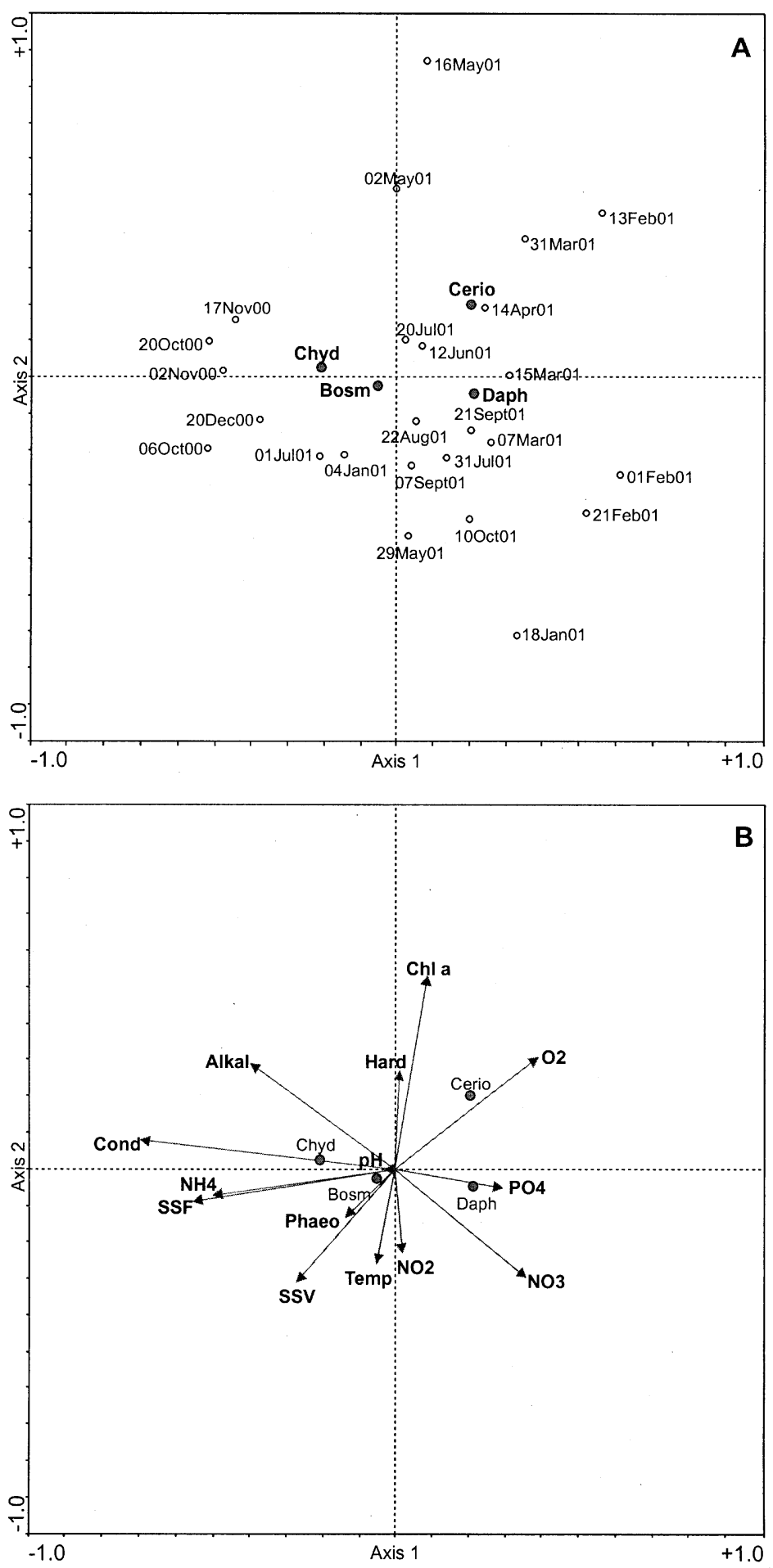

Fig. 5. Spatial ordination resulting from CCA of cladoceran taxa with respect to selected explanatory variables: A) biplot of cladoceran abundance and date scores for the studied period; B) biplot of cladoceran abundance and environmental variables scores for the studied period. See text for further explanation. Bosm - Bosmina longirostris; Cerio - Ceriodaphnia pulchella; Daph - Daphnia longispina; Chyd - Chydoridae. 
çalves et al. (1996) presented nutrient concentrations and Chl $a$ for the period of 1992-1993 in Lake Vela, when values were much more lower than in the present work. The more recent work by Fernandes (1999) also observed average nutrient and Chl $a$ values considerably lower to the ones presented here.

When one compares the cladoceran densities observed in the two former works (Vasconcelos 1990, Barros 1994) and in the present study it is also possible to observe differences. Small-bodied cladocerans, such as $B$. longirostris and Chydoridae, are presently much more abundant (10-20 fold). On the other hand, $C$. pulchella was not as abundant as observed in previous studies. However, we believe that the high densities of Daphnia in the summer resulted in the absence of a Ceriodaphnia-dominated phase. Furthermore, this chain of events may have been influenced by the May 29 fish kill, which lead to the sudden increase of Daphnia and Bosmina populations during the summer (see below).

The typical abundance diagram of northern temperate lakes was presented by Saunders et al. (1999). According to these authors, zooplankters have low abundances in the winter because of low temperatures and low food conditions. In spring, there is a succession from small to large zooplankton species until early summer, where cladocerans, mostly daphnids, dominate with high abundances (Dohet \& Hoffmann 1995, Hülsmann \& Weiler 2000). This is then followed by a shift from large forms to small-bodied forms, such as Ceriodaphnia or Diaphanosoma (Dohet \& Hoffmann 1995). More recently, Tessier \& Woodruff (2002) presented a categorization of lakes according to fish planktivory, which suggests that these general dynamics are mainly valid in shallow lakes, due to the absence of refuge from planktivores (in opposition to the deep-water refuge in summer-stratified lakes). Several factors have been pointed out as being responsible for the Daphnia midsummer decline (Hülsmann \& Weiler 2000). However, predation by juvenile fish (especially YOY) seems to be the most consensual hypothesis (Dohet \& Hoffmann 1995, Saunders et al. 1999, Hülsmann \& Weiler 2000), although interference and/or toxicity of summer cyanobacterial blooms cannot be put aside (Vasconcelos 1990, DeMott et al. 2001). A new zooplankton peak typically occurs in the autumn, while the winter is usually characterised by low abundances. This was the general pattern observed by Dohet \& Hoffmann (1995) in the Esch-sur-Sûre reservoir (Luxembourg), for example, as well as by Barros (1994) in Lake Vela.
The Ceriodaphnia-dominated phase observed in the summer by both Vasconcelos (1990) and Barros (1994) can be explained by three factors: competition, size-selective predation, and resistance to cyanobacteria. First of all, Ceriodaphnia can only prosper when large Daphnia are absent or at low densities. Under the same circumstances, Daphnia is a superior competitor than Ceriodaphnia and it has been experimentally shown that Daphnia spp. can suppress small species (Vanni 1986, Matveev et al. 2000), especially in eutrophic systems, where the competitive effects are more pronounced (Vanni 1986). In the summer, zooplankters are subjected to very high predatory pressure, especially because of YOY fish, and this pressure is sizeselective. This means that small Ceriodaphnia can flourish, while large Daphnia are decimated by zooplanktivorous fish. Additionally, Lampert (1982), De Bernardi and Giussani (1990) and Vasconcelos (1990) claimed that small species are more resistant to cyanobacteria (e.g. Microcystis aeruginosa) than Daphnia.

The major fish kill observed in May 29, probably as a consequence of complete oxygen depletion, gave rise to a summer Daphnia peak. Although the extent of the fish kill was not studied, it seems to have been drastic enough to diminish the predatory pressure on cladocerans. A Daphnia and, later, a Bosmina peak occurred during the summer, contrarily to the previously observed midsummer pattern. Competition with these taxa may have constrained the normal Ceriodaphnia midsummer peak. In fact, Fig. 4 shows that Ceriodaphnia was expanding and Daphnia was coming out of its spring abundance peak, prior to the fish kill. Therefore, this cladoceran dynamics presents a seasonal pattern that is different from the typical successional pattern. However, fish kills have been regularly observed in Lake Vela, as well as in other eutrophic systems, and their effects on the zooplanktonic community are not yet fully understood. The consequences of fish kills, such as the one recorded here, enhance the subtle or drastic role that fish have on the zooplankton communities, as discussed by Christofferson et al. (1993) and Jeppesen et al. (1999).

The CCA employed to the data did not reveal any clear trend, although a considerable amount of variability (34\%) was explained. Other data may be as important as the physico-chemistry of the lake, when attempting to extract the main explanatory variables from the cladoceran abundance pattern. The phytoplanktonic data matrix, as well as the level of predatory pressure (from fish), might have provided further explanatory information about the zooplankton variability. As discussed here, numerous factors determine 
the composition of the cladoceran assemblage and its temporal variability. Additional information on toxic cyanobacteria, YOY fish, competitive interactions within zooplankton, or anti-predator defences should be integrated in such models in order to fully comprehend the intricate trophic interactions of aquatic systems. Further research is needed for Lake Vela, in order to face its «old» problems, aiming at the implementation of adequate restoration measures.

\section{References}

Amoros C. 1984a.- Introduction pratique à la systématique des organismes des eaux continentales françaises. Crustacés cladocères. Bull. Soc. Linn. Lyon, 3 : 72-107.

Amoros C. 1984b. - Introduction pratique à la systématique des organismes des eaux continentales françaises. Crustacés cladocères (suite). Bull. Soc. Linn. Lyon, 4 : 120-144.

APHA, AWWA \& WPCF 1989. - Standard methods for the examination of water and wastewater - 17th Edition. American Public Health Association, Washington, DC, USA : $1467 \mathrm{p}$.

Barros P. 1994. - Implicações ecotoxicológicas de cianobactérias em cladóceros. M.Sc. thesis. Faculdade de Ciências e Tecnologia da Universidade de Coimbra, Coimbra, Portugal : $84 \mathrm{p}$.

Beaver J.R. \& Havens K.E. 1996. — Seasonal and spatial variation in zooplankton community structure and their relation to possible controlling variables in Lake Okeechobee. Freshwat. Biol., 36 : 45-56.

Christofferson K., Riemann B., Klysner A. \& Sondergaard M. 1993. - Potential role of fish predation and natural populations of zooplankton in structuring a plankton community in eutrophic lake water. Limnol. Oceanogr., 38 : 561-573.

De Bernardi R. \& Giussani G. 1990. — Are blue-green algae a suitable food for zooplankton? An overview. Hydrobiologia 200/201 : 29-41.

Dohet A. \& Hoffmann L. 1995. - Seasonal succession and spatial distribution of the zooplankton community in the reservoir of Esch-sur-Sûre (Luxembourg). Belg. J. Zool., 125 : 109-123.

DeMott W.R., Gulati R.D. \& Van Donk E. 2001. — Daphnia food limitation in three hypereutrophic Dutch lakes: evidence for exclusion of large-bodied species by interfering filaments of cyanobacteria. Limnol. Oceanogr., 46 : 2054-2060.

Fernandes M.J. 1999. - Modelação e simulação nas lagoas de Quiaios. Ph.D. thesis. Universidade do Algarve, Faro, Portugal : $236 \mathrm{p}$.

Gonçalves F., Ribeiro R., Vasconcelos V. \& Soares A.M.V.M. 1996. - Anthropogenic influences on seasonal changes of nutrients, physical and chemical factors in three coastal freshwater shallow lakes (Portugal). Limnetica, 12 : 47-52.

Hanazato T. 2001. - Pesticide effects on freshwater zooplankton: an ecological perspective. Environ. Pollut., 112:1-10.

Haney J.F. \& Hall D.J. 1973. — Sugar-coated Daphnia: a preservation technique for Cladocera. Limnol. Oceanogr., $18: 331-333$.

Hülsmann S. \& Weiler W. 2000. - Adult, not juvenile mortality as a major reason for the midsummer decline of a Daphnia population. J. Plankton Res., 22 : 151-168.
Jeppesen E., Jensen J.P., Sondergaard M. \& Lauridsen T. 1999. Trophic dynamics in turbid and clearwater lakes with special emphasis on the role of zooplankton for water clarity. Hydrobiologia, 408/409: 217-231.

Lampert W. 1982. — Further studies on the inhibitory effect of the toxic blue-green Microcystis aeruginosa on the filtering rate of zooplankton. Arch. Hydrobiol., 95 : 207-220.

Lind O.T. 1979. — Handbook of common methods in Limnology $2^{\text {nd }}$ Edition. The C.V. Mosby Company, St. Louis, USA : 199 p.

Lorenzen C.J. 1967. - Determination of chlorophyll and phaeopigments: spectrophotometric equations. Limnol. Oceanogr., 12 : 343-346.

Matveev V., Matveeva L. \& Jones G.J. 2000. — Relative impacts of Daphnia grazing and direct stimulation by fish on phytoplankton abundance in mesocosm communities. Freshwat. Biol., 44 : 375385.

Pereira R. 1997. - Plano de ordenamento e gestão das lagoas das Braças e da Vela (Centro-Litoral). M.Sc. thesis. Faculdade de Ciências e Tecnologia da Universidade de Coimbra, Coimbra, Portugal : $142 \mathrm{p}$.

Pereira R., Soares A.M.V.M., Ribeiro R. \& Gonçalves F. 2002. Assessing the trophic state of Linhos lake: a first step towards ecological rehabilitation. J. Environ. Manage., 64 : 285-297.

Saunders P.A., Porter K.G. \& Taylor B.E. 1999. - Population dynamics of Daphnia spp. and implications for trophic interactions in a small, monomictic lake. J. Plankton Res., 21 : 1823-1845.

Scourfield D.J. \& Harding J.P. 1966. - A key to the British freshwater Cladocera - $3^{\text {rd }}$ Edition. Scientific Publication $n^{\circ} 5$. Freshwater Biological Association, Ambleside, UK : 55 p.

Scheffer M. 1999. - The effect of aquatic vegetation on turbidity; how important are the filter feeders? Hydrobiologia, 408/409: 307-316.

Strickland J.D.H. \& Parsons T.R. 1972. — A practical handbook of seawater analysis - $2^{\text {nd }}$ Edition. Bulletin 167. Fisheries Research Board of Canada, Ottawa, Canada : $310 \mathrm{p}$.

ter Braak C.J.F. 1986. — Canonical correspondence analysis: a new eigenvector technique for multivariate direct gradient analysis. Ecology, 67 : 1167-1179.

ter Braak C.J.F. 1995. - Ordination. Pp 91-173 in Data analysis in community and landscape ecology - New Edition. Jongman R.H.G., ter Braak C.J.F. \& Tongeren O.F.R. (eds). Cambridge University Press, Cambridge, UK.

ter Braak C.J.F. \& Verdonschot P.F.M. 1995. — Canonical correspondence analysis and related multivariate methods in aquatic ecology. Aquat. Sci., 57 : 255-289.

Tessier A.J. \& Woodruff P. 2002. - Cryptic trophic cascade along a gradient of lake size. Ecology, 83 : 1263-1270.

Vanni M.J. 1986. - Competition in zooplankton communities: suppression of small species by Daphnia pulex. Limnol. Oceanogr. $31: 1039-1056$

Vasconcelos V.M. 1990. — Ecotoxicologia de cianobactérias: impacte dos seus «blooms» nas comunidades animais e sua aplicação na gestão da qualidade da água. Provas de Aptidão Pedagógica e Científica. Faculdade de Ciências da Universidade do Porto, Porto, Portugal : $82+51$.

Vasconcelos V.M., Campos T., Amorim A. \& Soares A.M.V.M. 1993. - Toxicidade de estirpes de cianobactérias isoladas a partir das lagoas das Braças, Vela e Mira (região Centro-litoral) - resultados preliminares. Bol. UCA, 1 : 164-172. 